\title{
Genç Futbolcularda Yüksek Şiddetli İnterval Antrenmanın Çeviklik Sürat ve Aerobik Performans Üzerine Etkisinin İncelenmesi
}

\author{
Bereket KÖSE $^{1} \quad$ Ahmet ATLI $^{2}$
}

\begin{abstract}
Özet
$\mathrm{Bu}$ çalışmanın amacı yüksek şiddetli interval antrenmanın genç futbolcularda çeviklik, sürat ve aerobik

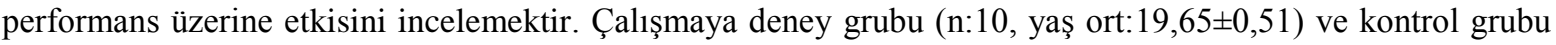
(n:10, yaş ort:18,88 $\pm 0,62)$ olmak üzere 20 genç futbolcu katılmıştır. Çalışmada deney grubu normal futbol antrenmanlarına ek olarak haftada $3 \mathrm{kez}$ yüksek şiddetli interval antrenman programını 7 hafta yapmıştır. Kontrol grubu ise sadece normal futbol antrenmanlarına devam etmiştir. Çalışmada ön test son test olarak proagility çeviklik testi, 30 metre sürat testi ve Yo-Yo aralıklı koşu testi uygulanmıştır. İstatistiksel hesaplamalar SPSS-20 paket programıyla yapılmış ve güven aralığı $\mathrm{p}<0,05$ olarak kabul edilmiştir. Yapılan bu çalışmada deney grubunun sürat ve Yo-Yo aralıklı koşu testi özelliklerinin ön test son test karşılaştırmalarında son test değerlerinin istatistiksel anlamda daha iyi olduğu görülmektedir $(\mathrm{p}<0,05)$. Deney grubunun çeviklik ön test son test değerlerinde ise bir faklılık gözlenmemiştir $(\mathrm{p}>0,05)$. Kontrol grubunun ön test son test sürat ve çeviklik özelliklerinde bir farklılık bulunmazken $(p>0,05)$ Yo-Yo aralıklı koşu testinde ise son test verileri anlamlı bir şekilde artış göstermiştir $(\mathrm{p}<0,05)$. Sonuç olarak yüksek şiddetli interval antrenman programlarının genç futbolcularda sürat ve aerobik dayanıklılığın bir göstergesi olan koşu mesafesini artırdığı görülmüştür.
\end{abstract}

Anahtar Kelimeler: Çeviklik, Futbol, İnterval, Sürat

\section{Investigation of the Effect of High Intensity Interval Training on Agility, Speed and Aerobic Performance in Young Football Players}

\begin{abstract}
The aim of this study is to investigate whether high intensity interval training has an effect on agility, speed and aerobic performance in young footballers. 20 football players, including experimental group (n: 10, age mean: $19.65 \pm 0.51$ ) and control group (n: 10 , age mean: $18.88 \pm 0.62$ ), participated in the study.In the study, in addition to normal football training, the experimental group made a high intensity interval training program 3 times a week for 7 weeks. The control group continued only normal football training. In the study, pro-agility agility test, 30 meter speed test and Yo-Yo interval running test were used as pre-test and post-test. Statistical calculations were made with the SPSS-20 package program and the confidence interval was accepted as $\mathrm{p}<0.05$. In this study, it was observed that the speed and Yo-Yo interval running test features of the experimental group were statistically better in the pre test-post test comparisons $(p<0.05)$. In this study, it was observed that the speed and Yo-Yo interval running test features of the experimental group were statistically better in the pre test-post test comparisons $(\mathrm{p}<0.05)$. No difference was observed in the agility pre test-post test values of the experimental group ( $\mathrm{p}>0.05)$. As a result, it has been observed that high intensity interval training programs increase running distance, which is an indicator of speed and aerobic endurance in young footballers.
\end{abstract}

Keywords - Agility, Football, Interval, Speed.

\footnotetext{
${ }^{T}$ Sorumlu Yazar: Şırnak Üniversitesi, Beden Eğitimi ve Spor Yüksekokulu, Şırnak-Türkiye,bereket.kose@hotmail.com, https://orcid.org/0000-0001-5315-9195

2 Iğdır Üniversitesi, Beden Eğitimi ve Spor Yüksekokulu, Iğdır-Türkiye,atliahmett@gmail.com, https://orcid.org/0000$\underline{0002-7516-2675}$
} 


\section{GíRiş}

Futbol içerisinde rol oynayan önemli faktörlere bakıldığında psikolojik (karar verme, stress, öz güven vs) ve fiziksel (tekniktaktik süreç, aerobik, anaerobik enerji vs) durumlar ciddi etken olarak görülmektedir (Gülle, Çetin, Şeker ve İhsan, 2017). Nitekim futbol, oyuncuların teknik, taktik ve fiziksel becerilere ihtiyaç duyduğu en yaygın spor türlerinden biri olarak kabul edilmektedir. Futbol performansının geliştirilmesi üzerine yapılan araştırmalar temel olarak teknik ve taktik özelliklerin dışında güç, hız ve dayanıklılık gibi fiziksel özelliklere de odaklanmaktadır (Helgerud, Engen, Wisloff ve Hoff, 2001). Futbol, tekrarlanan sprintlerin bulunduğu ve anaerobik enerji yolunun kabul edildiği aerobik tabanlı bir spor olarak bilinmektedir (Tomas, Chamari, Castagna ve Wisloff, 2005). Tekrarlı yapısı ile karakterize edilen futbolda, her 3-5 saniyelik periyotta farklı yapıda aktif değişiklikler meydana gelmektedir. Oyun esnasinda ortalama 30-40 adet sprint, 30-40 adet sıçrama, $15 \mathrm{~km}$ 'den daha hizlı 2-3 m sprint ve $20 \mathrm{~km}$ 'den daha hızlı $600 \mathrm{~m}$ sprint performansının uygulandığ 1 belirtilmektedir. Yeterli aerobik kapasite, tekrarlanan yüksek yoğunluklu aktiviteler ve toparlanma becerileri, futbolda başarılı olmak için gerekli fizyolojik gereksinimler olarak kabul edilmektedir (Bangsbo, Mohr ve Krustrup 2006; Tomas ve diğerleri, 2005).

Yapılan çalışmalar, oyuncuların bir futbol maçında \%3-7 aralığında yüksek yoğunluklu aktiviteler de dahil olmak üzere ortalama 10 ila $12 \mathrm{~km}$ arasında bir mesafeyi koştuklarını bildirmektedir (Bradley, Sheldon, Wooster, Olsen, Boanas ve Krustrup, 2009; Dellal ve diğerleri, 2011). Bunun da maksimum kalp atış hızının (HRmax) ortalama \%80-90'ına ve $\mathrm{VO}_{2}$ max'ın \%75-80'ine karşı1lı geldiği belirtilmektedir (Tomas ve diğerleri, 2005). Tüm maç boyunca koşu performansını etkileme potansiyeli olan fiziksel kapasiteler arasında; sürat, patlayıcı güç, tekrarlı sprint hızı ve çevikliğin muhtemelen en belirleyici parametreler olduğu bildirilmektedir (Buchheit, Villanueva, Simpson ve Bourdon, 2010). Bu nedenle, bu spesifik fiziksel kapasitelerin geliştirilmesi ve iyileştirilmesi antrenörler ve kondisyonerler için büyük ilgi çekmektedir. Teknik ve taktik yönler, oyuncuların kondüsyon düzeyi ile belirlenebilmekte ve bu nedenle son derece önemli olmaktadır. Modern futbol, oyuncuların başarı için büyük oranda önemli olan yüksek yoğunluklu aktiviteleri tekrarlayabilmeleri için enerji gerektiren bir spor olarak tanımlanmaktadır.

Araştırmalar, aerobik sistemin futboldaki ana enerji kaynağı olduğunu, yüklenme ve dinlenme süresi arasındaki ilişskinin önemini bildirmektedir. Daha yüksek aerobik kapasite seviyesi, bununla birlikte gecikmiş yorgunluğun oluşması ve oyun esnasında daha hızlı toparlanmanın koşu mesafelerindeki değişimin temel nedeni olarak gösterilmektedir (Helgerud ve diğerleri, 2001). Bu doğrultuda futbol antrenmanları hem aerobik kondisyon düzeyini hem de tekrarlanan sprint becerilerini artırmaya dayanmalıdır. Yüksek şiddetli interval antrenmanların (HIIT), güç ve sprint performansları üzerinde olumsuz bir etkisi olmadan oyuncuların genel aerobik kondisyon seviyelerini geliştirmek için etkili bir yöntem olduğu kabul edilmektedir (Bravo ve diğerleri, 2008). Yüksek şiddetli interval antrenmanların (HIIT) futbolculara önemli avantajlar sağladığ $; \quad \mathrm{VO}_{2} \max$, toparlanma süresi, koşu mesafesi ve tekrarlanan sprint kapasitesinde artış sağladığı kabul edilmektedir (Iaia, Rampinini ve Bangsbo, 2009). Krustrup ve ark. (2005), yüksek aerobik kapasiteye sahip futbolcuların maç sırasında en fazla koşu mesafesine sahip olduklarını bildirmektedir. Helgerud ve diğerleri (2001) ise, yüksek şiddetli interval antrenmanların (HIIT) $\mathrm{VO}_{2} \max$ seviyeleri başta olmak üzere futbolla ilişkili önemli performans parametrelerini geliştirdiğini belirtmektedir. Müsabaka sezonunda normal takım programına ek olarak, 10 haftalık yüksek şiddetli interval antrenman (HITT) programının oyuncuların aerobik kapasitesini arttırdığı ve bunun da genel takım performansında önemli gelişmeler sağladığı 
bildirilmektedir (Dupont, Akakpo ve Berthoin, 2004). Aerobik metabolizmanın performansa katkısının, tekrarlanan yüksek şiddetli interval antrenmanlar (HITT) ile olumlu derecede arttı̆̆ bildirilmektedir. Futbolda uygulanan anaerobik antrenmanın yanı sıra yüksek şiddetli interval antrenmanların dayanıklılık performansını ve dolayısıyla koşu mesafelerini geliştirdiği kabul edilmektedir (Howard ve Stavrianes, 2017). Ayrica, HITT antrenmanların kisa dinlenme aralıkları nedeniyle koşu yorgunluğu direnci ile birlikte oyuncuların futboldaki sprint performansını da arttırdı ğ1 bildirilmiştir (Hoff ve diğerleri, 2002).

Yüksek şiddetli interval antrenman, güç ve sprint performansı üzerinde yan etkileri olmayan aerobik kondisyonu iyileştirmek için iyi bir antrenman metodu olduğu kabul edilmektedir. Yüksek şiddetli interval antrenman, aerobik kondisyon ve futbola özgü dayanıklılığı arttırırken; futbolda başarıyı etkileyen önemli parametrelerden güç, sürat ve tekrarlı sprint performanslarında da etkili olmaktadır (Belegišanin, 2017). Sonuç olarak, yüksek şiddetli interval antrenmanın (HIIT), en önemli amaçlarından biri maksimum ve yüksek yoğunluklu egzersiz yapma yeteneğini geliştirmektir. HIIT'in farklı seviyelerdeki futbolcuların daha az zamanda bazı performans parametrelerinin gelişimi için uygulanabilir bir yöntem olduğu düşünülmektedir.

Araştırmanın Amacı: Genç futbolcularda yüksek şiddetli interval antrenmanın çeviklik, sürat ve aerobik performans üzerine etkisinin incelenmesidir.

\section{YÖNTEM}

Araştırma için Şırnak Üniversitesi Rektörlüğü Etik kurul başkanlığından yayın etiği izni alınmıştır. Araştırmada Helsinki bildirgesi etik kurallarında uyulmuştur.

Yapılan bu çalışmaya, yaşları ortalaması $19,65 \pm 0,51$ y1l, boyları ortalamas1 $1,78 \pm 0,068$ $m$ ve vücut ağırlıkları ortalaması $69,80 \pm 4,26$ $\mathrm{kg}$ olan 10 erkek futbolcu deney grubu olarak; yaşları ortalaması $18,88 \pm 0,62$ yıl, boyları ortalaması $1,77 \pm 0,050 \mathrm{~m}$ ve vücut ağırlıkları ortalamas1 $68,66 \pm 5,56 \mathrm{~kg}$ olan 10 genç erkek futbolcu da kontrol grubu olarak katılmıştır. Çalışmaya katılan futbolcular randomize bir şekilde deney ve kontrol grubu olarak 2 gruba ayrılmıştır. Deney grubu dayanıklılık antrenmanları hariç kendi rutin antrenmanlarına ek olarak, 7 hafta süreyle, haftada 3 gün yüksek şiddetli interval antrenman programına katılmışlardır. Kontrol grubu ise normal antrenmanlarina devam etmişlerdir. Çalışma grubu oluşturulurken katılımcıların son iki ayda herhangi bir ciddi yaralanma sürecinde olmamalarına ve antrenmanlarını aksatmama esaslarına dikkat edilmiştir. İlk olarak katılımcıların boy uzunlukları $0.01 \mathrm{~mm}$ hassasiyetinde boy ölçer kullanılarak belirlenmiştir. Daha sonra vücut ağırlıkları Tanita Bc 730 marka 0.01 gr hassasiyetinde dijital tartı ile tespit edilmiştir. Futbolcuların maksimal kalp atım hızlarını tespit etmek için ön Yo-Yo birinci seviye aralıklı koşu testi yapılmış olup testi biraktıkları an Polar Team sistemi ile maksimal kalp atım hızları tespit edilmiştir.

\section{Antrenman Programi ve Kullanilan Testler} Kontrol grubu rutin futbol antrenman1 gerçekleştirmiştir. Deney grubu ise dayanıklılık antrenmanları hariç normal rutin futbol antrenmanına ek olarak haftanın 3 günü de yüksek şiddetli interval antrenmanı yapmıştır. Literatür incelendiği zaman yüksek şiddetli interval antrenman programları genel olarak maksimal kalp atım hızının $\% 90$ ve üstü değerlere denk geldiği görülmüş̧ür (Gibala ve Mc Gee, 2008; Gibala ve Mc Gee, 2012). Bu sebeple bu çalışmanın protokolü oluşturulurken Arazi ve arkadaşlarının uyguladıkları yöntem kullanılmıştır. $\mathrm{Bu}$ antrenman yönteminde yüksek şiddetli interval antrenmanı maksimal kalp atım hızının yaklaşık \%90'1 ile 90 saniye koşu ve 90 saniye yürüyüş şeklinde 7,5 dakika boyunca yapılmış ve bu seri 1 set olarak kabul edilmiştir. Çalışma 3 set üzerinden yapılmış olup setler arasında 2 dakika dinlenme aralığ 1 verilmiştir (Arazi ve diğerleri, 2017). Yüksek şiddetli interval antrenmanlarına başlamadan önce her iki gruba $30 \mathrm{~m}$ sürat testi, pro-agility çeviklik testi ve bir gün sonra Yo-Yo 1 testi ön test olarak uygulanmıştır. 7 haftalık yüksek 
şiddetli interval antrenmanları sona erdikten sonra her iki gruba da $30 \mathrm{~m}$. sürat testi, proagility çeviklik ve Yo- Yo 1 testi ölçümü son test olarak tekrar yapılmıştır.

\section{Test protokolï}

İlk gün katılımcıların yaşları, vücut ağırlıkları ve boy uzunlukları tespit edildikten sonra 30 metre sürat ve çeviklik testleri yapılmıştır. Ertesi gün ise Yo-Yo seviye 1 aralıklı koşu testi uygulanıp katılımcıların hem koştukları mesafe hem polar team sistemi ile de maksimal kalp atım hızları belirlenmiştir. 7 hafta sonra ise katılımciların son testleri aynı şekilde yapılmıştır.

\section{0 metre sürat testi}

Katılımcıların süratlerini belirlemek için 30 metre sprint testleri uygulanmıştır. Fotoseller 0 ve 30 metrelik mesafelere yerleştirilmiştir. Katılımcılar teste başlamadan önce 10 dakika 1sınma koşusu sonrası 7 dakika dinamik germe ve kısa sprint hareketlerinin bulunduğu bir ısınma protokolü gerçekleştirmiştir. Katılımcılar testi 5 dakika dinlenme aralığ sonrası iki kez yapmıştır. İki denemenin en iyi zamanı kaydedilmiştir. Katılımcı hazır olduğunda başlangıç fotoselinin bir metre gerisinden başlayarak çıkış yaptı ve ulaşabildiği en yüksek hızla $30 \mathrm{~m}$ mesafedeki bitiş fotoseline vardıktan sonra koşu süresi otomatik olarak kaydedilmiştir.

\section{Pro-agility çeviklik testi}

Pro-agility çeviklik test alanı, başlangıç çizgisinin 4,57 $\mathrm{m}$ soluna ve sağına işaretlerin yerleştirilmesi şeklinde belirlenmiştir. Başlangıç çizgisine fotosel kapısı yerleştirilmiştir. Tekrarlı geçiş zamanları bu sayede alınabilmiştir. Teste başlamadan önce katılımcı başlangıç çizgisinde hazır hale gelir. Teste başladığında önce sağdaki işarete, sonra da soldaki ișarete dokunarak başlangıç çizgisinden geçerek testi sonlandırır (Bayraktar, 2013; Özbay ve diğerleri, 2018).

\section{Yo-Yo aralıklı toparlanma testi (seviye 1)}

Yo-yo Aralıklı Toparlanma Testi, her gidiş gelişin sonunda 10 saniyelik dinlenmeyi içeren toplamda 40 metrelik bir testtir. Koşu "A" noktasından "B" noktasına doğru yapılır ve bu noktalara varınca sinyal sesi beklenir sinyal sesi gelince tekrar diğer noktaya koşulur. Koşu hızı test protokolüne göre artış gösterip, sporcu A noktasina geldiğinde ilk defa sinyali yakalayamazsa hata alır ve ikinci sinyal sesi duyulduğunda " $A$ " noktasında olamazsa test sonlandırılır. Sporcu başlangıç noktası olan "A" noktasina her gelişinde test mesafesi kâğıdına işaretlenerek kaydedilir (Castanga ve ark., 2006; Krustup ve ark., 2003; Svensson ve Drust, 2004). Yo-Yo Aralıklı Toparlanma-1 Testinin koşu hızı 10 $\mathrm{km} / \mathrm{s}$ hızla başlayıp her $40 \mathrm{~m}$ sonunda test protokolü koşu hızını $0,5 \mathrm{~km} / \mathrm{s}$ ya da $1 \mathrm{~km} / \mathrm{s}$ arttırmaktadır (Bangsbo ve ark., 2008).

\section{Istatistiksel analiz.}

Verilerin değerlendirilmesinde, SPSS 20 istatistik programı kullanıldı. Verilerin normal dağılım gösterip göstermediğini belirlemek için Shapiro-Wilk testi yapılmıştır. Veriler normal dağılım gösterdiğinden ön test ve son test değerlerinin karşılaştırılmasında bağımlı $\mathrm{t}$ testi kullanılmıştır. İstatistik işlemler için güven aralığ $\mathrm{p}<0,05$ kullanılmıştır.

\section{BULGULAR}

Tablo 1'de deney grubunun sürat ön test son test değerlerinde istatistiksel anlamda bir fark ortaya çıkmıştır. Buna göre son test değerleri ön test değerlerinden daha iyi çıkmıştır $(p<0,05)$. Kontrol grubunda ise ön test son test değerlerinde istatistiksel bir fark yoktur $(\mathrm{p}>0,05)$. 
Köse, B., Atlı, A. / Genç futbolcularda yüksek şiddetli interval antrenmanın çeviklik sürat ve aerobik performans üzerine etkisinin incelenmesi

Tablo 1. Futbolcuların Sürat Ön ve Son Test Değerlerinin Grup İçi Karşılaştırılması

\begin{tabular}{clccc}
\hline Değişkenler & & Ortalama \pm Ss & t & P \\
\hline \multirow{2}{*}{ Deney } & Sürat ön test (s) & $4,08 \pm 0,09$ & & \\
& Sürat son test (s) & $4,04 \pm 0,08$ & 2,764 & $0,02^{*}$ \\
& Sürat ön test (s) & $4,09 \pm 0,05$ & 1,000 & 0,34 \\
\multirow{2}{*}{ Kontrol } & Sürat son test (s) & $4,08 \pm 0,05$ & & \\
& & & & \\
\hline
\end{tabular}

$* \mathrm{p}<0,05 ;$ s: saniye

Tablo 2. Futbolcularin Çeviklik Ön ve Son Test Değerlerinin Grup Içi Karşılaştırılması

\begin{tabular}{lllcc}
\hline Değişkenler & & Ortalama \pm Ss & t & p \\
\hline \multirow{2}{*}{ Deney } & Çeviklik ön test (s) & $4,90 \pm 0,68$ & & 0,20 \\
& & & 1,367 & \\
\multirow{2}{*}{ Kontrol } & Çeviklik son test (s) & $4,88 \pm 0,57$ & & \\
& Çeviklik ön test (s) & $4,89 \pm 0,04$ & & 0,53 \\
& Çeviklik son test (s) & $4,90 \pm 0,05$ & $-2,228$ & \\
\hline
\end{tabular}

s:Saniye

Tablo 2'de hem denek hem de kontrol grubunun çeviklik ön test son test

değerlerinde istatistiksel anlamda bir fark bulunamamıştır $(\mathrm{p}>0,05)$.

Tablo 3. Futbolcuların Yo- Yo Koşu Testi Ön ve Son Test Değerlerinin Grup İçi Karşılaştırılması

\begin{tabular}{lllcl}
\hline Değişkenler & & Ortalama \pm Ss & $\mathrm{t}$ & $\mathrm{p}$ \\
\hline \multirow{2}{*}{ Deney } & Yo-yo ön test (m) & $1517,1 \pm 120,77$ & & \\
& Yo-yo son test (m) & $1823,6 \pm 97,98$ & $-15,91$ & $0,001^{*}$ \\
& Yo-yo ön test (m) & $1476,8 \pm 49,12$ & & \\
\multirow{2}{*}{ Kontrol } & Yo-yo son test (m) & $1607,6 \pm 54,38$ & $-15,76$ & $0,001^{*}$ \\
& & &
\end{tabular}

$* \mathrm{p}<0,05 ; \mathrm{m}:$ metre

Tablo 3'de hem kontrol hem de deney grubunun Yo-yo koşu testi değerlerinde istatistiksel anlamda son test lehine bir farkl1lık bulunmuştur. Buna göre her iki

grubun 7 haftalı antrenman sonucu koşu mesafeleri istatistiksel anlamda artmıştır $(\mathrm{p}<0,05)$. 


\section{TARTIŞMA ve SONUÇ}

Bu çalışma futbol antrenmanlarına ek olarak 7 haftalık yüksek şiddetli interval antrenman (HIIT) programlarının genç erkek futbolcuların 30 metre süratlerine, çevikliklerine ve aerobik performanslarına etki edip etmediği araştırılmıştır. Çalışmanın sonuçlarına bakıldığında deney grubunda olan futbolcuların sürat özelliklerinin 7 hafta sonunda (ön test: 4,08 $\pm 0,68$ saniye ; son test: $4,04 \pm 0,08 \mathrm{~s} ; \mathrm{p}<0,02) \% 1$ gelişim gösterdiği görülmüştür. Yo-yo aralıklı koşu testinde ise hem deney grubu (ön test: $1517,1 \pm 120,77$; son test: $1823,6 \pm 97,98 ; \mathrm{p}<0,01)$ hem de kontrol grubunun (ön test: 1476,8 $\pm 49,12$; son test: $1607,6 \pm 54,38 ; \mathrm{p}<0,01)$ son testleri sırasıyla yaklaşık $\% 20$ ve $\% 9$ artmıştır. $\mathrm{Bu}$ çalışmada 7 haftalık HIIT antrenmanın çeviklik performansında etkisi olmadığ görülmüştür.

Futbolda ağırlıklı olarak aerobik enerji sistemi kullanılmasına rağmen oyunun akışında sürat, çeviklik gibi anaerobik sistem bileşenlerini de kapsar (Hazır ve diğerleri, 2009). Futbolcular üzerinde yapılan çalışmalar incelendiği zaman yüksek şiddetli interval antrenmanların sürat performansını arttırdığı gözlenmiştir (Ak1lveren, 2018; Gökkurt, 2019; Howard ve Stavrianeas, 2017; Sperlich ve diğerleri, 2011; Wong ve diğerleri, 2010). Nitekim yüksek şiddetli interval antrenmanların takım sporları için oldukça etkili bir yöntem olduğu çeşitli formlarıla, kardiyovasküler sistemi, metabolik fonksiyonları ve sporcuların fiziksel performansını da geliştiren etkili antrenman yöntemlerinden biri olduğu vurgulanmaktadır (Gibala ve Mcgee, 2012).

Sporcunun hareketler serisi boyunca hızlı bir şekilde yön değiştirirken, hızlanırken, kısa sürede vücut pozisyonunu kontrol etme ve devam ettirebilmesi çevikliğine bağlıdır (Asadi 2012; Günay ve Ş1ktar 2017). Daha önce yapılan çalışmalar incelendiğinde şiddetli interval antrenmanlarının çevikliği arttırdığ1 görülürken (Akılveren, 2018; Gökkurt, 2019; Iacono ve diğerleri, 2015) bizim çalışmamızda diğer çalışmaların aksine yüksek şiddetli interval antrenmanların çeviklik üzerinde anlamlı derecede olumlu bir etkisinin olmadığı sonucuna varılmıştır.
Howard ve Stavrianeas yaptıkları çalışma bizim çalışmanın sonuçlarını desteklemektedir (Howard ve Stavrianeas, 2017). Akılveren ise şiddetli interval antrenmanlarının çevikliği olumlu yönde etkilediğini vurgulamasına rağmen bu durumu muhtemelen antrenmanlara oluşan adaptasyon nedeniyle olduğunu yorumlamıştır (Akılveren, 2018).

Hem yüksek şiddetli interval antrenman programı hem de rutin futbol antrenmanının Yo-yo aralıklı koşu testinde hem deney hem de kontrol gruplarının aerobik dayanıklılık performansını (koşu mesafesi) sırasıyla \%20 ve $\% 9$ artırdığ 1 görülmüştür. HIIT antrenmanları sonucu daha fazla kas lifi, kalp damar ve solunum sistemini uyardığ için hem aerobik kapasitede hem de anaerobik kapasitenin gelişmesinde etkilidir (Karp, 2000; Gillen ve diğerleri, 2010; Gharah ve diğerleri, 2014). Örneğin Sperlich ve arkadaşları ile Helgerud ve arkadaşlarının yaptıkları çalışmada 5-8 haftalık HIIT antrenmanindan sonra futbolcularin VO2max'ını \%7 ile \%11 arasında artırdığını rapor etmişlerdir (Sperlich ve diğerleri, 2011; Helgerud ve diğerleri, 2001). Aynı şekilde Impellizzeri ve arkadaşlarının yaptığı çalışmada da benzer VO2max artı̧̧1 görülmüştür (Impellizzeri ve diğerleri, 2005). Yapılan bir başka çalışmada yüksek şiddetli interval antrenmanlarının koşu mesafesini \%25 artırdığı bildirilmiştir (Akılveren, 2018). Nitekim bizim çalışmamıza benzer yapılan bu çalışmanın sonuçları birbirine paraleldir. Çeşitli yazarlar tarafından yüksek şiddetli interval antrenman programinın futbolda aerobik gücü artırmak için geleneksel dayanıklılık yüklemelerine uygun bir alternatif olduğu hipotezini destekledikleri kimi yazarlar ise hem aerobik hem de anaerobik kapasiteleri geliştirmede etkili bir yöntem olduğu vurgulanmaktadır (Arazi ve diğerleri, 2017; Howard ve Stavrianeas, 2017).

Sonuç olarak yüksek şiddetli interval antrenmanlarının genç futbolcularda hem koşu mesafesini hem de sürat özelliğini 
geliştirdiği görülmüştür. Bunun yanı sıra zaman bakımından ekonomik olmasından bu antrenman metodunun futbolcuların antrenman programında yer alması gerektiği düşünülmektedir.

\section{KAYNAKÇA}

Akılveren, E. (2018). Futbolda Yüksek Şiddetli Interval Antrenman ve Tekrarlı Sprint Antrenmanlarının Aerobik Performans Üzerine Etkisinin İncelenmesi. Akdeniz Üniversitesi Să̆llk Bilimleri Enstitüsü. Yüksek Lisans Tezi.

Arazi, H., Keihaniyan, A., Eatemadyboroujeni, A., Oftade, A., Takhsha, S., Asadi, A., \& Ramirez-Campillo, R. (2017). Effects of Heart Rate Vs. Speed-Based High Intensity Interval Training on Aerobic and Anaerobic Capacity of Female Soccer Players. Sports, 5(3), 57.

Asadi, A.(2012). Effects of Six Weeks Depth Jump and Counter Movement Jump Training on Agility Performance. Roudbar Branch Islamic Azad University, Roudbar, Iran. Sport Science, 5, 67-70.

Bangsbo, J., Mohr, M., Krustrup, P. (2006). Physical and Metabolic Demands of Training and Match-Play in The Elite Football Player. Journal of Sports Sciences, 24(7): 665-74.

Bayraktar, I. (2013). Elit Boksörlerin Çeviklik, Sürat, Reaksiyon ve Dikey Siçrama Yetileri Arasındaki İlișkiler. Akademik Bakış Dergisi, 35, 1-8.

Belegišanin, B. (2017). Effectsof High-Intensity Interval Training on Aerobic Fitness in Elite Serbian Soccer Players. Exercise and Quality of Life Journal. 9(2): 13-17.

Bradley, PS, Sheldon, W., Wooster, B., Olsen, P., Boanas, P., and Krustrup, P. (2009). High Intensity Running in English FA Premier League Soccer Matches. J Sports Sci, 27:159-168.

Bravo, DF., Impellizzeri, FM., Rampinini, E., Castagna, C., Bishop, D., Wisloff, U. (2008). Sprint vs. Interval Training in
Football. Int J Sports Med., 29 (8): 668674.

Buchheit, M., Mendez-Villanueva, A., Simpson, BM., Bourdon, PC. (2010). Match Running Performance and Fitness in Youth Soccer. Int J Sports Med 31: 818825.

Castagna, C., Impellizzeri, F.M., Chamari, K., Carlomagno, D., Rampinini, E. (2006). Aerobic Fitness and Yo-Yo Contionus And Intermittent Tests Performances in Soccer Players: A Correlation Study. Journal Of Strength And Conditioning Research, 20(2): 320-325.

Dellal, A., Chamari, C., Wong, DP., Ahmaidi, S., Keller, D., Barros, MLR., Bisciotti, GN., and Carling, C. (2011). Comparison of Physical and Technical Performance in European Professional Soccer MatchPlay: The FA Premier League and La LIGA. Eur J Sport Sc 11: 51-59, 2011.

Dupont, G., Akakpo, K., Berthoin, S. (2004). The Effect of In-Season, High-Intensity Interval Training in Soccer Players. Journal of Strength and Conditioning Research, 18(3),584-589.

Gharah, D.N., Kordi, M.R., \& Gaeini, A.A. (2014). The effect of 4-week high intensity interval aerobic training VO2max, TMAX, VO2max of Iranian club soccer players. Biol. Exerc. Sci, 17, 47-57.

Gibala, M.J, Mcgee, S.L. (2008). Metabolic Adaptations to Short Term High İntensity Interval Training: A Little Pain for A Lot of Gain?. Exercise and Sport Sciences Reviews, 36(2), $58-63$.

Gibala, M.J., McGee, S.L. (2012). Physiological Adaptations to Low-Volume, HighIntensity İnterval Training in Health and Disease. J Physiol, 59:1077-1084.

Gillen, J. B., Percival, M. E., Skelly, L. E., Martin, B. J., Tan, R. B., Tarnopolsky, M. A., \& Gibala, M. J. (2014). Three minutes of all-out intermittent exercise per week increases skeletal muscle oxidative capacity and improves cardiometabolic health. PloS one, 9(11). 
Gökkurt, K. (2019). U19 Futbolcularda 8 Haftalık Yüksek Yoğunluklu İnterval Antrenmanın Sürat, Çeviklik ve İvmelenme Üzerine Etkisi. Selçuk Üniversitesi Sağllk Bilimleri Enstitüsü Yüksek Lisans Tezi.

Gülle, M., Çetin, M. Ç., Şeker, R., \& İhsan, S.(2017). Assessment of the Correlation Between Self-Esteem In DecisionMaking and Decision-Making Styles of Football Referees in Terms of Their Refereeing Experience and Violence Perceptions. International Journal of Sport Culture and Science, 5(3), 112-123.

Günay, M., Şıktar, E.(2017). Antrenman Bilimi, Ankara. Gazi Kitapevi Tic. Ltd. Şti,.

Hazır, T., Mahir, Öf., Açıkada, C. (2009). Genç Futbolcularla Çeviklik ile Vücut Kompozisyonu ve Aerobik Güç Arasındaki İlişki. Hacettepe Üniversitesi, Spor Bilimler Dergisi, Issn, 21, 146-53.

Helgerud, J., Engen, L.C., Wisløff, U., \& Hoff, J. (2001). Aerobic endurance training improves soccer performance. Medicine \& Science in Sports \& Exercise, 33(11), 1925-1931.

Hoff, J., Wisloff, U., Engen, L., Kemi, O., Helgerud, J. (2002). Soccer Specific Aerobic Endurance Training. British Journal of Sports Medicine, 36, 218-221.

Howard, N., Stavrianeas, S.(2017). In-Season High-İntensity İnterval Training İmproves Conditioning in High School Soccer Players. International Journal of Exercise Science, 10, 713.

Iacono, A.D., Eliakim, A., Meckel, Y.(2015). Improving Fitness of Elite Handball Players: Small-Sided Games Vs. HighIntensity Intermittent Training. The Journal of Strength \& Conditioning Research, 29, 83543.

Iaia, FM., Rampinini, E., Bangsbo, J. (2009). High-Intensity Training in Football. Int $J$ Sports Physiol Perform 4(3): 291-306.
Impellizzeri, F.M., Marcora, S.M., Castagna, C., Reilly, T., Sassi, A., Iaia, F.M., \& Rampinini, E. (2006). Physiological and performance effects of generic versus specific aerobic training in soccer players. International journal of sports medicine, 27(06), 483-492.

Karp, J. R. (2000). Interval training for the fitness professional. Strength \& Conditioning Journal, 22(4), 64.

Krustrup, P., Mohr, M., Amstrup, T., Rysgaard, T., Johansen, J., Steensberg, A., Pedersen, P.K., Bangsbo, J. (2003). The Yo-Yo Intermittent Recovery Test: Physiological Response, Reliability, And Validity. Medicine And Science In Sports and Exercise, 35(4): 697-705.

Krustrup, P., Mohr, M., Ellingsgaard, H., Bangsbo, J. (2005). Physical Demands During an Elite Female Soccer Game: Importance of Training Status. Med Sci Sports Exerc., 37(7):1242-1248.

Özbay, S., Ulupınar, S., \& Özkara, A.B. (2018). Sporda Çeviklik Performansı. Ulusal Spor Bilimleri Dergisi, 2(2), 97-112.

Sperlich, B., De Marées, M., Koehler, K., Linville, J., Holmberg, H.C., Mester, J.(2011). Effects of 5 Weeks of High-İntensity Interval Training Vs. Volume Training in 14-Year-Old Soccer Players. The Journal of Strength Conditioning Research, 25, 1271-8.

Svensson, M., Drust, B. (2004). Testing Soccer Players. Journal of Sports Sciences. 23 (6):601-618

Tomas, S., Chamari, K., Castagna, C., Wisloff, U. (2005). Physiology of Soccer. Sports Med., 35(6): 501-36.

Wong, P.L., Chaouachi, A., Chamari, K., Dellal, A., Wisloff, U. (2010). Effect of Preseason Concurrent Muscular Strength and High-İntensity İnterval Training in Professional Soccer Players. The Journal of Strength Conditioning Research, 24, 653-60. 